\title{
Anterior cruciate ligament reconstruction combined to partial knee replacement in active patients with ACL deficiency and knee osteoarthritis
}

\section{Claudio Legnani , Stefano Muzzi , Giuseppe M Peretti , Enrico Borgo \& Alberto Ventura}

To cite this article: Claudio Legnani , Stefano Muzzi , Giuseppe M Peretti , Enrico Borgo \& Alberto Ventura (2020): Anterior cruciate ligament reconstruction combined to partial knee replacement in active patients with ACL deficiency and knee osteoarthritis, The Physician and Sportsmedicine, DOI: $10.1080 / 00913847.2020 .1795558$

To link to this article: https://doi.org/10.1080/00913847.2020.1795558

Accepted author version posted online: 11 Jul 2020.

Submit your article to this journal $\pi$

Q View related articles $\longleftarrow$

View Crossmark data $\nearrow$ 
Publisher: Taylor \& Francis \& Informa UK Limited, trading as Taylor \& Francis Group

Journal: The Physician and Sportsmedicine

DOI: $10.1080 / 00913847.2020 .1795558$

TITLE PAGE

Title: Anterior cruciate ligament reconstruction combined to partial knee replacement in active patients with $A C L$ deficiency and knee osteoarthritis

Article Type: Review Article

First Author: Claudio Legnani ${ }^{1}, \mathrm{MD}$

Order of Authors: Claudio Legnani ${ }^{1}, \mathrm{MD}$

Stefano Muzzi ${ }^{2}$

Giuseppe M Peretti ${ }^{1,3}$

Enrico Borgo ${ }^{1}$, MD

Alberto Ventura ${ }^{1}, \mathrm{MD}$

Keywords: Unicompartmental knee replacement; medial osteoarthritis; anterior cruciate ligament; ACL reconstruction;

Authors Institutions: 1) IRCCS Istituto Ortopedico Galeazzi, Milan Italy 2) University of Milan, Milan, Italy 3) Department of Biomedical Sciences for Health, University of Milan, Milan, Italy.

Corresponding Author: Claudio Legnani, MD Tel +3902487851 , Fax +390248785233 , email: claudio.legnani@grupposandonato.it

Conflict of interest statement: All authors declare that they have no conflict of interest. 


\section{ABSTRACT}

Objectives: To report, through a systematic review of the literature, the clinical and radiographic outcomes of unicompartmental knee replacement (UKR) combined to anterior cruciate ligament $(\mathrm{ACL})$ reconstruction. It was hypothesized that this combined technique is a safe and effective procedure providing satisfactory post-operative functional outcomes.

Methods: A systematic review was performed by searching Pubmed/MEDLINE, CINAHL, SCOPUS, Embase and Ovid. Only studies in English pertaining all levels of evidence reporting on subjects with medial osteoarthritis and ACL deficiency undergoing UKR combined to ACL reconstruction were considered. Review articles and expert opinion or editorial pieces were excluded. Outcomes of interest included indications, clinical assessment including activity level, associated procedures, rate of complications such as revision surgery

Results: Overall, 9 studies met all the inclusion criteria for this review. All were published between 2006 and 2019. The search resulted in one comparative case series (Level III), four prospective cohort studies (Level III) and four case series (Level IV). From these studies, 249 patients were identified.

Conclusions: The combination of UKR and ACL reconstruction appears a safe and effective procedure providing satisfying outcomes and limited complications in selected patients with medial $\mathrm{OA}$ and $\mathrm{ACL}$ insufficiency. Further comparative studies reporting long-term outcomes are needed, as high-level studies on this topic are lacking.

Keywords: medial osteoarthritis; unicompartmental knee replacement; anterior cruciate ligament; $A C L$ reconstruction; activity level

Level of evidence: $V$, Systematic review 


\section{INTRODUCTION}

The treatment of unicompartmental knee osteoarthritis $(O A)$ in young and active patients with anterior cruciate ligament $(A C L)$ deficiency is an issue of debate [1-4].

Older patients are more likely to suffer from pain related to OA, and develop secondary ACL failure as a result of the degenerative process [3]. Conversely, in younger patients, an untreated primary ACL rupture typically leads to recurrent giving-way episodes associated to posterior femoral subluxation, posteromedial compartment wear and ultimately medial OA [5].

Traditional treatment options have ranged from joint distraction [6], to high tibial osteotomy (HTO) with and without ACL reconstruction [7, 8], to total knee replacement (TKR) [1]. Bone-conserving options are preferred for younger patients with higher physical demands, and the need for reduced invasiveness, bone stock preservation, and faster recovery time, as well as improved knee kinematics had led the way to the development of a new surgical strategy. In order to overcome the shortcomings related to $T K R$, recently a treatment option combining medial unicompartmental knee replacement (UKR) and ACL reconstruction has been proposed [920], since there is general agreement that UKR alone should not be performed in ACLdeficient knees [3].

Although early satisfactory outcomes were reported, still limited experience exists in this field. The purpose of our article is to report, through a systematic review of the literature, clinical and radiographic outcomes of UKR combined to $A C L$ reconstruction, focusing on useful decisionmaking criteria guiding surgeons to the most appropriate therapeutic approach for the ACLdeficient knee in the osteoarthritic knee.

\section{MATERIALS AND METHODS}

\section{Types of studies}

In the present review only studies in English pertaining all levels of evidence reporting on subjects with medial $O A$ and $A C L$ deficiency undergoing UKR combined to $A C L$ reconstruction were 
considered. Date limits were set between 1990 to 2019 to allow a review of recent data. We excluded review articles and expert opinion or editorial pieces.

\section{Search strategy}

Searches were carried out using the following string on Pubmed/MEDLINE, SCOPUS and Embase: ((anterior cruciate ligament reconstruction) OR (ACL reconstruction)) AND ((unicompartmental knee replacement) OR (unicompartmental knee prosthesis) OR (unicompartmental knee arthroplasty) OR (unicondylar knee arthroplasty) OR (unicondylar knee prosthesis) OR (unicondylar knee replacement)). The Preferred Reporting Items for Systematic Reviews and Meta-analysis (PRISMA) guidelines were used [21]. The abstracts of all hits were reviewed and duplicates were sorted out. The full texts of the selected articles obtained were evaluated for eligibility. References were hand screened for relevant citations to identify any articles not included in the primary search.

\section{Data extraction}

Study characteristics such as year of publication, study population, level of evidence, mean age, male/female ratio, follow-up duration, type of prosthesis, type of surgical intervention (either staged or combined) were extracted and collected by two reviewers, and checked by a third. An electronic database was created. Outcomes of interest included indications, clinical assessment including activity level, associated procedures, rate of complications such as revision surgery.

\section{RESULTS}

\section{Search results}

Overall, the search query yielded 1394 results. After duplicates were sorted out, 604 articles were screened for eligibility on the basis of title and abstract. Overall, 11 studies whose fulltext articles were assessed for eligibility met all the inclusion criteria for this review. One article reported redundand data and one was a technical note with no reported outcomes and were therefore excluded, thus leaving 9 studies to be included in the present review 
(Fig. 1). All were published between 2006 and 2019. The search resulted in one comparative case series (Level III) [19], four prospective cohort studies (Level III) $[9,12,16,18]$ and four case series (Level IV) $[11,13,17,20]$. Average follow-up periods ranged from 2 years to 7.8 years in a longterm study. From these studies, $\mathbf{2 6 3}$ patients were identified. Table 1 provides an overview of the characteristics of the studies considered.

\section{Indications}

The indications for this type of surgical management include patients with a primary ACL tear who develop secondary medial OA [5]. Only two studies $[9,12]$ reported which was the main complaint of the patients between medial knee pain and instability and performed one- or two-stage approach accordingly.

\section{Radiological assessment}

OA was diagnosed pre-operatively using long-leg standing and standard radiographs; in four studies $[12,13,18,19]$ valgus stress radiographs in $20^{\circ}$ of flexion were performed. Only in two studies magnetic resonance imaging (MRI) was performed to evaluate the knee joint preoperatively $[17,19]$. Post-operative standard $x$-rays were performed to assess positioning of the implant and presence of radiolucent lines in the majority of studies. In five studies $[11,13,18-20]$ radiological outcomes included long-leg standing radiographs in order to compare pre- and postoperative leg alignment.

\section{Surgical technique}

In two papers $[9,12]$, a total of 29 patients underwent a two-staged procedure, while in all other patients ACL reconstruction and UKR were performed in the same sitting.

\section{Anteroposterior laxity}

Tinius et al [13] quantified postoperative antero-posterior laxity using Rolimeter (Aircast, Summit, NJ, USA) and reported a reduction in the maximal anterior translation to less than $5 \mathrm{~mm}$ in 24 
patients (88.9\%). The KT-1000 arthrometer (MEDmetric Corp., San Diego, CA, USA) was used in one of the studies considered to instrumentally assess the amount of anteroposterior dislocation [17]. An improvement in mean residual differential laxity, with a a side-to-side difference of $2.8 \mathrm{~mm}$ at the most recent follow-up was reported [17].

\section{Prosthesis design}

Four studies report on the implantation of mobile-bearing designs $[9,12,16,18]$, while in other four studies a fixed-bearing design was adopted $[11,13,17,20]$. Only one retrospective casecontrol study comparing the outcomes of mobile bearing UKRs with those of fixed-bearing ones during combined ACL reconstruction and medial UKR did not report any statistically significant difference between different prosthesis designs regarding mid-term clinical and radiological outcomes [19]

\section{Graft choice}

Most studies used ipsilateral autologous hamstring autografts for ACL reconstruction [13, 16-20]. Two studies did not discriminate between the outcomes of the two surgical techniques in a mixed population of autologous bone-patellar tendon-bone (BPTB) and hamstring grafts $[11,12]$. Weston-Simmons et al [9] did not report any statistical difference in the clinical outcomes or survival between those patients who had BPTB grafts and those who had hamstring grafts.

\section{Complication rates}

Overall, the following major complications were reported: two deep infections $[\mathbf{9}, \mathbf{1 2}]$, in three cases insert dislocation of a mobile bearing occurred $[9, \mathbf{1 8}]$, in six cases, due to pain persistence and symptomatic lateral osteoarthritis, conversion to TKR was performed $[9,16,17,20]$. Survivorship of the implant ranged from $87.5 \%$ to $100 \%$. The highest failure rate $(12.5 \%)$ was reported by Iriberri et al. [20]. None reported graft failures. One study reported complications arising from external meniscus tear [20]. 


\section{DISCUSSION}

Based on the data present in literature, UKR combined to ACL reconstruction appears a safe and effective procedure in the treatment of unicompartmental OA in association with ACL deficiency: satisfying outcomes and limited complications were reported, although these data should be interpreted with caution because of the low-quality evidence of the studies included.

Medial osteoarthritis in conjunction with antero-posterior laxity in middle-aged patients is still an issue of debate, as evidence lacks on whether to treat unicompartmental $O A$ in association with ACL deficiency [22].

Concerning indications, consensus exists among surgeons that the decision whether to perform this combined procedure should rely on whether the primary issue is ACL incompetence or medial OA. Young and active subjects with an untreated ACL tear are more likely to develop secondary posteromedial OA, due to recurrent instability leading to posterior femoral subluxation [5]. In these cases, the other compartments keep their integrity, and ACL reconstruction combined to UKR could be a treatment option [12]. In contrast, in older patients suffering from primary medial $O A$, the $A C L$ may be damaged as a result of the degenerative process and additional pathologic changes such as involvement of the lateral compartment and shortening of the medial collateral ligament may occur [3]. These patients are therefore not good candidate for this combined procedure and may benefit from a TKR [18]. Since this combined approach ideally suits to the young and active population, there are concerns that improved knee function may result in increased physical demands on the joint. For this reason, most surgeons agree that patients' compliance is critical and that appropriate patient selection should be taken into account in order to maximize the outcomes.

Radiological assessment is mandatory to check the integrity of the lateral compartment and some authors suggest the use of valgus stress radiographs to assess the tension of the medial collateral ligament. MRI studies are not performed on a regular basis, and ACL tears are mainly diagnosed clinically or with the use of diagnostic arthroscopy. 
According to our findings, selected and motivated patients affected by unicompartmental OA in conjunction with ACL deficiency may experience considerable recovery of function and stability after combined and ACL reconstruction, with favorable outcomes in this patient population with regard to subjective and objective scores. An improvement in Tegner post-operative outcome scores was reported in four studies $[9,12,16,18]$, including a total of 165 patients, thus showing that the majority of patients returned to their pre-injury activity levels.

No graft failures were reported. This may be related to the fact that most of middle-aged patients do not return to sports involving pivoting, cutting, and jumping, thus preventing the risk of re-injury. In addition the osteoarthritic process as well as the impact of the surgical operation could have increased joint stiffness.

Only in two papers $[9, \mathbf{1 2}]$, a total of 29 patients underwent a two-staged procedure while in all other patients ACL reconstruction and UKR were performed in the same sitting. Authors who performed two-staged procedures reserved this approach to patients for whom the main complaint was knee instability and performed ACL reconstruction first followed by UKR for persistent pain; conversely, one-staged procedure whose chosen for patients complaining about medial knee pain.

Advantages of a combined procedure include shorter hospitalization and reduced costs without the need for two surgical procedures. Drawbacks include a more technicallydemanding procedure, potential graft impingement and undersizing of the tibial base plate as well as postoperative stiffness. Clinical results do not suggest significant differences between the two approaches.

As regards the mobile- or fixed-bearing prosthesis design, the first ones are advocate to result in low wear and loosening rates although carry the drawbacks of potential inlay dislocation. However, no difference between different prosthesis designs regarding mid-term clinical and radiological outcomes was reported, as previously outlined in literature [23].

According to our findings, insert dislocation of a mobile bearing implant occurred in three patients $[9,18]$. Fixed-bearing prostheses have been suggested to allow appropriate implant 
placement and subsequently optimize ligament tension, since their technical features do not rely on natural tension in the ligaments while implanting the components $[14,17]$.

Implant survivorship ranged from $87.5 \%$ to $100 \%$. The majority of implant failures requiring revision to TKR were due to prosthetic joint infection or symptomatic lateral osteoarthritis. The main limit of this systematic review is that there was a considerable lack of high-level studies supporting the combination of UKR and ACL reconstruction. However, the growing body of papers may change the approach of surgeons towards the management of the young and active patient suffering from $O A$ and $A C L$ insufficiency.

Further comparative studies are required in order to drive the surgeons to determine the correct therapeutic approach for the patient with concomitant medial OA and ACL deficiency. There is potential for this method of treatment to become more mainstream, but further research is warranted, thus physicians' practice and expertise still represent the most useful tool in clinical practice.

\section{CONCLUSIONS}

Although technically demanding, the combination of UKR and ACL reconstruction appears a safe and effective procedure providing satisfying outcomes and limited complications in selected patients with medial OA and ACL insufficiency. The literature on this subject is limited and further comparative studies reporting long-term outcomes are needed, as high-level studies on this topic are lacking.

\section{CONFLICT OF INTEREST STATEMENT}

All authors declare that they have no conflict of interest.

\section{REFERENCES}

[1] Williams RJ III, Wickiewicz TL, Warren RF. Management of unicompartmental arthritis in the anterior cruciate ligament deficient knee. Am J Sports Med 2000;28:749-760 
[2] Simon D, Mascarenhas R, Saltzman BM, et al. The Relationship between Anterior Cruciate Ligament Injury and Osteoarthritis of the Knee Adv Orthop 2015;928301

[3] Mancuso F, Hamilton TW, Kumar V, et al. Clinical outcome after UKA and HTO in ACL deficiency: a systematic review. Knee Surg Sports Traumatol Arthrosc 2016;24:112-122 [4] Citak M, Bosscher MR, Citak M, et al Anterior cruciate ligament reconstruction after unicompartmental knee arthroplasty. Knee Surg Sports Traumatol Arthrosc 2011:19:1683-1688. [5] Lee YS, Jeong YM, Sim JA, Kwak et al. Specific compartmental analysis of cartilage status in double-bundle ACL reconstruction patients: a comparative study using pre- and postoperative MR images. Knee Surg Sports Traumatol Arthrosc 2013;21:702-707

[6] van der Woude JAD, Wiegant K, van Heerwaarden RJ, et al. Knee joint distraction compared with high tibial osteotomy: a randomized controlled trial. Knee Surg Sports Traumatol Arthrosc. 22017;25: 876-886

[7] Cantivalli A, Rosso F, Bonasia DE, et al. High Tibial Osteotomy and Anterior Cruciate Ligament Reconstruction/Revision. Clin Sports Med. 2019;38:417-433.

[8] Li Y, Zhang H, Zhang J, et al. Clinical outcome of simultaneous high tibial osteotomy and anterior cruciate ligament reconstruction for medial compartment osteoarthritis in young patients with anterior cruciate ligament-deficient knees: a systematic review. Arthroscopy 2015;31:507-519 [9] Weston-Simons JS, Pandit H, Jenkins C, et al. Outcome of combined unicompartmental knee replacement and combined or sequential anterior cruciate ligament reconstruction: a study of 52 cases with mean followup of five years. J Bone Joint Surg Br 2012;94:1216-1220 [10] Dervin GF, Conway AF, Thurston P. Combined anterior cruciate ligament reconstruction and unicompartmental knee arthroplasty: surgical technique. Orthopedics 2007;30:39-42 [11] Krishnan SRSR, Randle R. ACL reconstruction with unicondylar replacement in knee with functional instability and osteoarthritis. J Orthop Surg Res 2009;4:43

[12] Pandit H, Beard DJ, Jenkins $C$, et al. Combined anterior cruciate ligament reconstruction and Oxford unicompartmental knee arthroplasty. J Bone Joint Surg Br 2006;88:887-892

[13] Tinius M, Hepp P, Becker R. Combined unicompartmental knee arthroplasty and anterior cruciate ligament reconstruction. Knee Surg Sports Traumatol Arthrosc 2012;20:81-87 
[14] Ventura A, Legnani C, Terzaghi C, et al. Medial unicondylar knee arthroplasty combined to anterior cruciate ligament reconstruction. Knee Surg Sports Traumatol Arthrosc. 2015;25:675-680 [15] Volpin A, Kini SG, Meuffels DE. Satisfactory outcomes following combined unicompartmental knee replacement and anterior cruciate ligament reconstruction. Knee Surg Sports Traumatol Arthrosc. 2018;26:2594-2601

[16] Kennedy JA, Molloy J, Mohammad HR, et al. Mid- to long-term function and implant survival of ACL reconstruction and medial Oxford UKR. Knee 2019;26:897-904

[17] Ventura A, Legnani C, Terzaghi C, et al. Unicompartmental Knee Replacement Combined to Anterior Cruciate Ligament Reconstruction: Midterm Results. J Knee Surg 2019 [Epub ahead of print]

[18] Tian S, Wang B, Wang Y, et al. Combined unicompartmental knee arthroplasty and anterior cruciate ligament reconstruction in knees with osteoarthritis and deficient anterior cruciate ligament. BMC Musculoskelet Disord. 2016;5:327

[19] Tecame A, Savica R, Rosa MA, et al. Anterior cruciate ligament reconstruction in association with medial unicompartmental knee replacement: a retrospective study comparing clinical and radiological outcomes of two different implant design. Int Orthop 2019;43:2731-2737 [20] Iriberri I, Suau S, Payán L, et al Long-term deterioration after one-stage unicompartmental knee arthroplasty and anterior cruciate ligament reconstruction. Musculoskelet Surg. 2019 Dec;103(3):251-256

[21] Moher D, Liberati A, Tetzlaff J, et al The PRISMA Group. Preferred Reporting Items for Systematic Reviews and Meta-Analyses: The PRISMA Statement. PLoS Med 2009;67: e1000097 [22] Plancher KD, Dunn ASM, Petterson. The anterior cruciate ligament-deficient knee and unicompartmental arthritis. Clin Sports Med 2014;33: 43-55

[23] Whittaker JP, Naudie DD, McAuley JP, et al Does bearing design influence midterm survivorship of unicompartmental arthroplasty? Clin Orthop Relat Res 2010;468:73-81

\section{CAPTIONS TO FIGURES}


Fig. 1: PRISMA flow diagram showing the number of studies identified, screened and included in the present review 
Table 1. Characteristics of included studies

\begin{tabular}{|c|c|c|c|c|c|c|c|c|c|c|}
\hline Author & Year & $\begin{array}{l}\text { Patient } \\
\text { S } \\
\text { number }\end{array}$ & $\begin{array}{l}\text { Level of } \\
\text { evidence }\end{array}$ & $\begin{array}{l}\text { Mean age } \\
\text { (range) }[S D \\
]\end{array}$ & $\begin{array}{l}\text { Male/femal } \\
\text { e ratio }\end{array}$ & $\begin{array}{l}\text { Mean } \\
\text { follow-up } \\
\text { (range) [SD } \\
]\end{array}$ & $\begin{array}{l}\text { Bearin } \\
\text { g type }\end{array}$ & Graft type & $\begin{array}{l}\text { Single- } \\
\text { stage } \\
\text { approac } \\
h(\%)\end{array}$ & $\begin{array}{l}\text { Complication } \\
s \text { (rate) }\end{array}$ \\
\hline Pandit & $\begin{array}{l}200 \\
6\end{array}$ & 15 & $\begin{array}{l}\text { III } \\
\text { Prospective } \\
\text { cohort study }\end{array}$ & $\begin{array}{l}49.8(36- \\
60)\end{array}$ & $13: 2$ & $\begin{array}{l}2.8(2.5- \\
4.3) \text { years }\end{array}$ & Mobile & $\begin{array}{l}3 \text { BPTB } \\
11 \\
\text { Hamstring } \\
\text { s }\end{array}$ & $\begin{array}{l}4 / 15 \\
(26.7 \%)\end{array}$ & $\begin{array}{l}1(6.7 \%) \\
\text { Infection and } \\
\text { two-stage } \\
\text { revision to a } \\
\text { TKR }\end{array}$ \\
\hline $\begin{array}{l}\text { Krishna } \\
\mathrm{n}\end{array}$ & $\begin{array}{l}200 \\
9\end{array}$ & 9 & $\begin{array}{l}\text { IV } \\
\text { Retrospectiv } \\
\text { e case series }\end{array}$ & $56(50-64)$ & $5: 4$ & $\begin{array}{l}24(12-60) \\
\text { months }\end{array}$ & Fixed & $\begin{array}{l}8 \text { BPTB } \\
1 \\
\text { Hamstring } \\
\mathrm{s}\end{array}$ & $\begin{array}{l}9 / 9 \\
(10\end{array}$ & None \\
\hline Tinius & $\begin{array}{l}201 \\
2\end{array}$ & 27 & $\begin{array}{l}\text { IV } \\
\text { Retrospectiv } \\
\text { e case series }\end{array}$ & $44(38-53)$ & $11: 16$ & $\begin{array}{l}50(9-71) \\
\text { months }\end{array}$ & Fixed & $\begin{array}{l}\text { Hamstring } \\
\mathrm{s}\end{array}$ & $\begin{array}{l}27 / 27 \\
(100 \%)\end{array}$ & None \\
\hline $\begin{array}{l}\text { Weston- } \\
\text { Simons }\end{array}$ & $\begin{array}{l}201 \\
2\end{array}$ & 51 & $\begin{array}{l}\text { III } \\
\text { Prospective } \\
\text { cohort study }\end{array}$ & $51(36-67)$ & $40: 11$ & $\begin{array}{l}60(12-120) \\
\text { months }\end{array}$ & Mobile & $\begin{array}{l}\text { (?) BPTB } \\
\text { (?) } \\
\text { Hamstring } \\
\text { s }\end{array}$ & $\begin{array}{l}33 / 51 \\
(64.7 \%)\end{array}$ & $\begin{array}{l}1(2 \%) \\
\text { Infection and } \\
\text { two-stage } \\
\text { revision to a } \\
\text { TKR } \\
1(2 \%) \\
\text { Bearing } \\
\text { dislocation } \\
1(2 \%) \\
\text { Symptomatic } \\
\text { lateral } \\
\text { osteoarthritis } \\
\text { and } \\
\text { conversion to } \\
\text { TKR }\end{array}$ \\
\hline Tian & $\begin{array}{l}201 \\
6\end{array}$ & 28 & $\begin{array}{l}\text { III } \\
\text { Prospective } \\
\text { cohort study }\end{array}$ & $\begin{array}{l}50.5 \\
60)\end{array}$ & 10:18 & $\begin{array}{l}52(24-96) \\
\text { months }\end{array}$ & Mobile & $\begin{array}{l}\text { Hamstring } \\
\mathrm{s}\end{array}$ & $\begin{array}{l}28 / 28 \\
(100 \%)\end{array}$ & $\begin{array}{l}2(7 \%) \\
\text { Bearing } \\
\text { dislocation }\end{array}$ \\
\hline Iriberri & $\begin{array}{l}201 \\
8\end{array}$ & & $\begin{array}{l}\text { IV } \\
\text { Retrospectiv } \\
\text { e case series }\end{array}$ & $52(42-60)$ & $5: 3$ & $\begin{array}{l}175(117- \\
258) \\
\text { months }\end{array}$ & Fixed & $\begin{array}{l}\text { Hamstring } \\
\mathrm{s}\end{array}$ & $\begin{array}{l}8 / 8 \\
(100 \%)\end{array}$ & $\begin{array}{l}1(12.5 \%) \\
\text { Symptomatic } \\
\text { lateral } \\
\text { osteoarthritis } \\
\text { and } \\
\text { conversion to } \\
\text { TKR } \\
1(12.5 \%) \\
\text { external } \\
\text { meniscus tear } \\
\text { repair }\end{array}$ \\
\hline Tecame & $\begin{array}{l}201 \\
9\end{array}$ & 24 & $\begin{array}{l}\text { III } \\
\text { Retrospectiv } \\
\mathrm{e} \\
\text { comparative } \\
\text { study }\end{array}$ & $\begin{array}{l}47.8(41- \\
53) \\
48.4(43- \\
54)\end{array}$ & $20: 4$ & $\begin{array}{l}53[8.3] \\
\text { months } \\
42[6.7] \\
\text { months }\end{array}$ & $\begin{array}{l}9 \\
\text { Mobile } \\
15 \\
\text { Fixed }\end{array}$ & $\begin{array}{l}\text { Hamstring } \\
\mathrm{s}\end{array}$ & $\begin{array}{l}24 / 24 \\
(100 \%)\end{array}$ & None \\
\hline $\begin{array}{l}\text { Kenned } \\
\mathrm{y}\end{array}$ & $\begin{array}{l}201 \\
9\end{array}$ & 75 & $\begin{array}{l}\text { III } \\
\text { Prospective } \\
\text { cohort study }\end{array}$ & $\begin{array}{l}52.6(36- \\
71)\end{array}$ & $59: 16$ & $\begin{array}{l}6.4(1-15) \\
\text { years }\end{array}$ & Mobile & $\begin{array}{l}\text { Hamstring } \\
\mathrm{s}\end{array}$ & $\begin{array}{l}58 / 75 \\
(76 \%)\end{array}$ & $\begin{array}{l}3(3.9 \%) \\
\text { revisions to } \\
\text { TKR }\end{array}$ \\
\hline Ventura & $\begin{array}{l}201 \\
9\end{array}$ & 12 & $\begin{array}{l}\text { IV } \\
\text { Retrospectiv } \\
\text { e case series }\end{array}$ & 54 [3.9] & $8: 4$ & $\begin{array}{l}7.8(6-10) \\
\text { years }\end{array}$ & Fixed & $\begin{array}{l}\text { Hamstring } \\
\mathrm{s}\end{array}$ & $\begin{array}{l}12 / 12 \\
(100 \%)\end{array}$ & $\begin{array}{l}1(8.3 \%) \\
\text { Symptomatic } \\
\text { lateral } \\
\text { osteoarthritis }\end{array}$ \\
\hline
\end{tabular}


SD: Standard deviation; BPTB: Bone-Patellar tendon-Bone; TKR: Total knee replacement

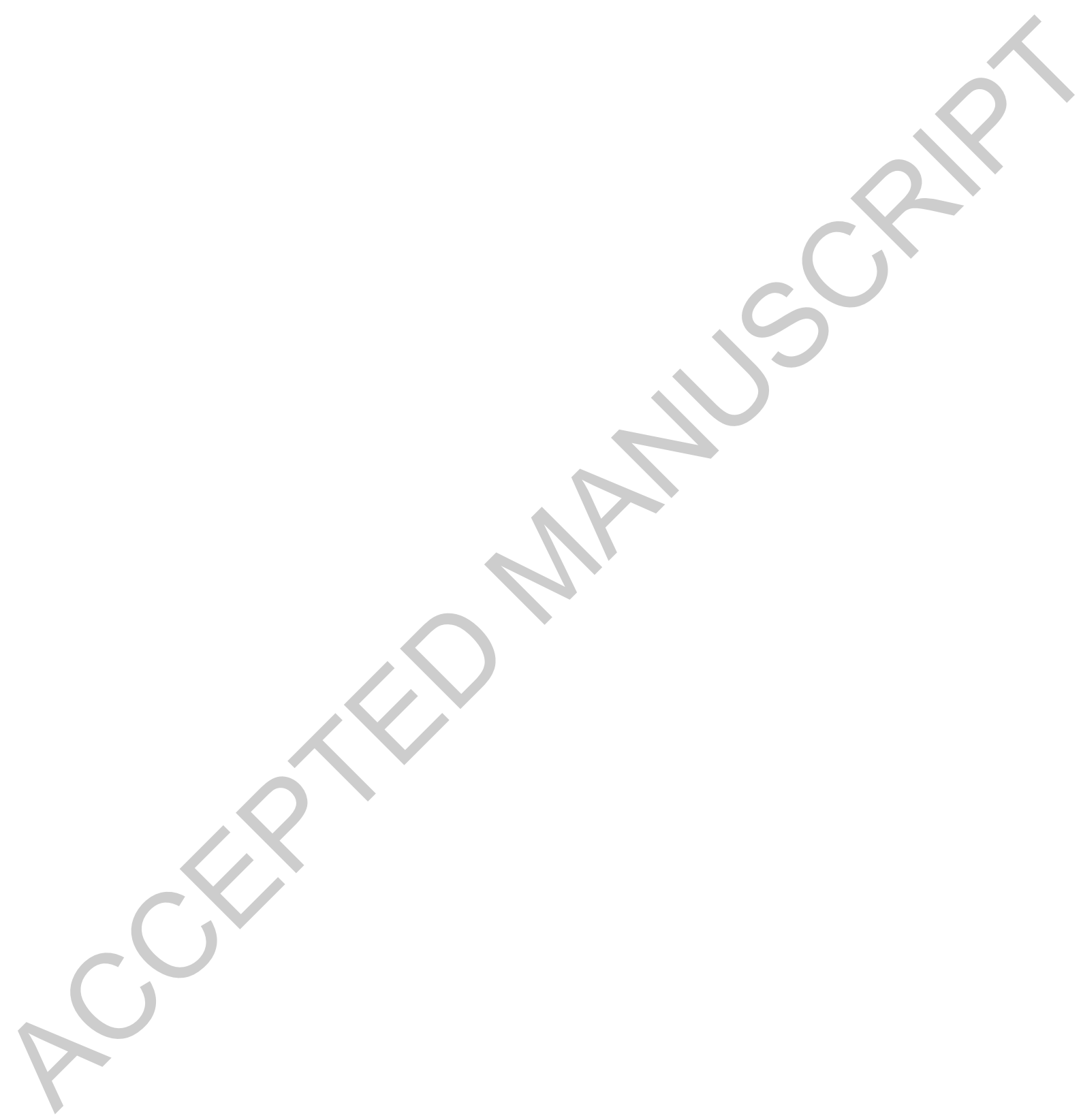


Table 2. Summary of functional and clinical outcomes utilized in included studies

\begin{tabular}{|c|c|c|c|c|}
\hline Author & Year & Outcome measures & $\begin{array}{l}\text { Pre-op mean score } \\
\text { (range) }[S D]\end{array}$ & $\begin{array}{l}\text { Post-op mean score } \\
\text { (range) }[S D]\end{array}$ \\
\hline Pandit & 2006 & $\begin{array}{l}\text { OKS } \\
\text { KSS Objective } \\
\text { KSS Functional } \\
\text { Tegner Activity Level }\end{array}$ & $\begin{array}{l}29(17-36) \\
55(25-83) \\
85(65-90) \\
1.6(1-3)\end{array}$ & $\begin{array}{l}46(37-48) \\
99(95-100) \\
96(85-100) \\
3.8(3-6)\end{array}$ \\
\hline Krishnan & 2009 & $\begin{array}{l}\text { WOMAC index of osteoarthritis } \\
\text { OKS } \\
\text { KSS }\end{array}$ & $\begin{array}{l}45(35-52) \\
23.5(20-58) \\
135(64-167)\end{array}$ & $\begin{array}{l}24(21-27) \\
11(10-12) \\
196(190-200)\end{array}$ \\
\hline Tinius & 2011 & $\begin{array}{l}\text { Knee Society Score } \\
\text { KSS Objective } \\
\text { KSS Functional }\end{array}$ & $\begin{array}{l}77.1[11.6] \\
38.4[10] \\
38.7[8.8]\end{array}$ & $\begin{array}{l}166[12.1] \\
83.2[6.8] \\
82.7[8.2]\end{array}$ \\
\hline $\begin{array}{l}\text { Weston- } \\
\text { Simons }\end{array}$ & 2012 & $\begin{array}{l}\text { OKS } \\
\text { AKS Functional Score } \\
\text { AKS Objective Score } \\
\text { Tegner Activity Score }\end{array}$ & $\begin{array}{l}28(16-46) \\
82(45-100) \\
40(25-80) \\
2.5(1-5)\end{array}$ & $\begin{array}{l}41(17-48) \\
95(45-100) \\
75(25-95) \\
3.5(1-5)\end{array}$ \\
\hline Tian & 2016 & $\begin{array}{l}\text { OKS } \\
\text { KSS objective } \\
\text { KSS functional } \\
\text { Tegner Activity Level }\end{array}$ & $\begin{array}{l}31[7.1] \\
60.4[7.1] \\
63.7[6.5] \\
4.4[1.2]\end{array}$ & $\begin{array}{l}43[4.2] \\
84.5[6.3] \\
86.9[5.3] \\
5.3[0.8]\end{array}$ \\
\hline Iriberri & 2018 & $\begin{array}{l}\text { KSS } \\
\text { WOMAC index of osteoarthritis } \\
\text { VAS }\end{array}$ & $\begin{array}{l}94(62-165) \\
59(3-81) \\
8(6-10)\end{array}$ & $\begin{array}{l}154(102-200) \\
26(1-52) \\
3(0-7)\end{array}$ \\
\hline Tecame & 2019 & $\begin{array}{l}\text { WOMAC index of oste } \\
\text { KSS functional } \\
\text { KSS objective }\end{array}$ & $\begin{array}{l}55.8[7.6] \text { mobile, } 59[8.1] \\
\text { fixed } \\
71.2[7.4] \text { mobile, } 70.2[6.4] \\
\text { fixed } \\
37.3[4.3] \text { mobile, } 38.6[3.8] \\
\text { fixed }\end{array}$ & $\begin{array}{l}79.3[7.3] \text { mobile, } 81.3[7.6] \\
\text { fixed } \\
86.2[6.2] \text { mobile, } 84.7[5.9] \\
\text { fixed } \\
73.4[9.3] \text { mobile, } 77.3[10.5] \\
\text { fixed }\end{array}$ \\
\hline Kennedy & 2019 & $\begin{array}{l}\text { OKS } \\
\text { Tegner Activity Level }\end{array}$ & $\begin{array}{l}29.0[8] \\
2.8[1]\end{array}$ & $\begin{array}{l}41(11-48) \\
3.6(0-8)\end{array}$ \\
\hline Ventura & 019 & $\begin{array}{l}\text { KOOS } \\
\text { OKS } \\
\text { WOMAC index of osteoarthritis } \\
\text { AKS Objective Score } \\
\text { AKS Functional Score } \\
\text { Mean side-to-side anterior laxity in mm }\end{array}$ & $\begin{array}{l}62.4[8.1] \\
28.8[10.1] \\
71.9[11.5] \\
45[12.9] \\
80[14.2] \\
5.7[1.4]\end{array}$ & $\begin{array}{l}80.2[11.7] \\
42.4[8.9] \\
84.9[9.3] \\
75[13.5] \\
88[16.2] \\
2.8[0.9]\end{array}$ \\
\hline
\end{tabular}

SD : Standard deviation ; KOOS: Knee Osteoarthritis Outcome Score; OKS: Oxford Knee Score; KSS: Knee Society Score; WOMAC: Western Ontario and McMaster; AKS: American Knee Society; 


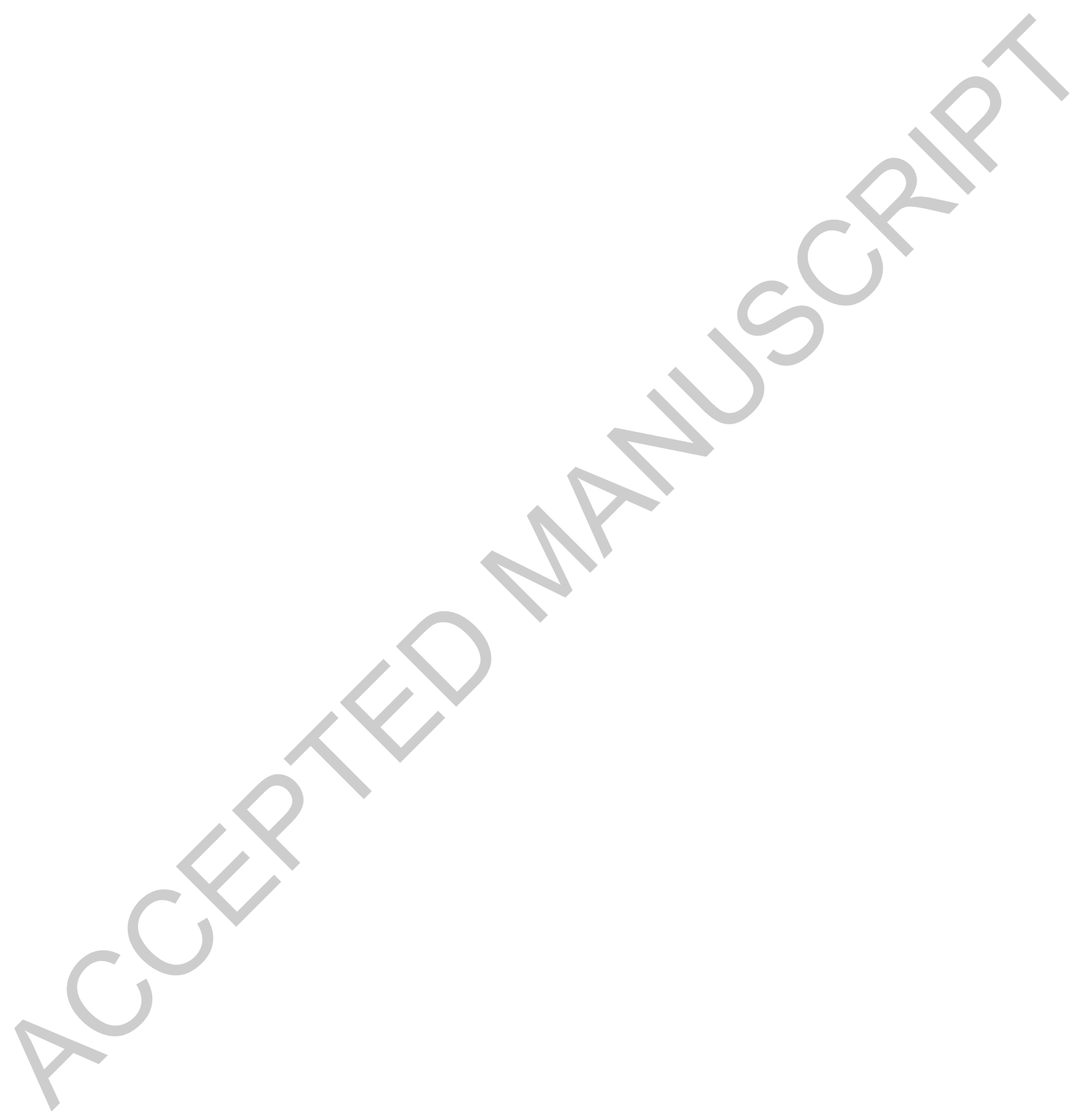



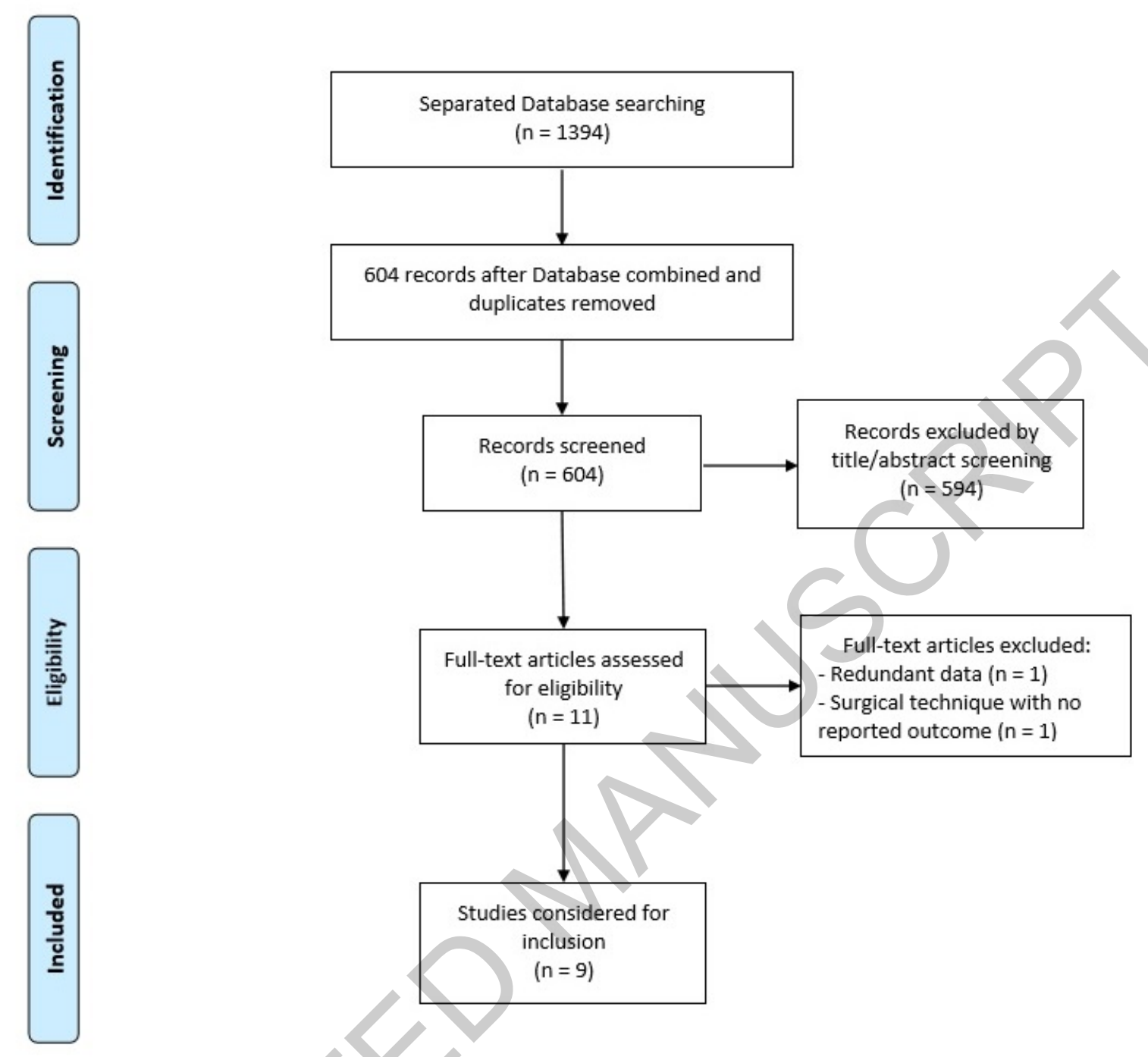

Fig 1 